Revista Iberoamericana, Vol. LXXIX, Núm. 242, Enero-Marzo 2013, 163-180

\title{
HISTORIAS DE METAMORFOSIS: \\ LO ABYECTO, LOS LÍMITES ENTRE LO ANIMAL Y LO HUMANO, EN LA LITERATURA CENTROAMERICANA DE POSGUERRA
}

POR

YANSI Y. PÉREZ

Carleton College

La literatura de posguerra centroamericana se ha leído desde diferentes paradigmas que a veces privilegian el desencanto y otras veces la violencia; también se ha interpretado como una respuesta a los procesos neoliberales que caracterizan esta época en la región. El desencanto se explica como la desilusión total con los proyectos utópicos que caracterizaron las guerras revolucionarias en varios de los países del Istmo. Según Misha Kokotovic, en su artículo "Neoliberal Noir: Contemporary Central American Crime Fiction as Social Criticism", este desencanto con el imaginario de la revolución no significa una acogida de los proyectos de esa nueva forma de utopía que son los proyectos de corte neoliberal surgidos en los años noventa en la región. De forma similar, Ana Patricia Rodríguez insiste en que esta nueva ficción "construye un imaginario centroamericano transnacional donde los desechos son el signo principal de las condiciones contradictorias del momento de paz” (31, énfasis en el original).

Beatriz Cortez, por su parte, en su trabajo "Estética del cinismo: la ficción centroamericana de posguerra”, propone leer la ficción de esta época como un regreso a espacios más íntimos, alejados de la esfera pública que ocupaban los testimonios que surgieron durante los años ochenta; asimismo, cree que esta nueva ficción debe verse como un intento de esta nueva generación de escritores de reescribir las versiones oficiales de lo que es la identidad centroamericana, ya no desde los foros de denuncia forjados por el género testimonio sino desde espacios alternos como "la intimidad", que se vinculan a "la construcción de la subjetividad". El mismo Horacio Castellanos Moya, escritor de esta generación, ante la pregunta sobre lo que piensa de la nueva generación de escritores “cínicos” comenta: “Esa generación ‘cínica’ o ‘impasible’ [...] está embarcada en los valores esenciales del ser humano: las pasiones, las envidias, los odios, los amores, los celos... La literatura debe tocar esas cosas que no cambian, para tener más libertad y mucha mayor trascendencia” (“La violencia”).

Ya que los factores (la desigualdad socio-económica, la violencia, etc.) que contribuyeron al estallido de guerras en el istmo no han desparecido, el momento de 
posguerra, como bien explicaAlexandra Ortiz Wallner en su trabajo titulado “Transiciones democráticas/transiciones literarias. Sobre la novela centroamericana de posguerra” sigue obligando a los escritores a responder a esta realidad sumamente desoladora, y muchos lo hacen con la "creación de un nuevo lenguaje y la constitución de un espacio desde el cual se narran las violencias”. En términos generales, podría decirse que los rasgos que caracterizan esta nueva literatura son: desplazamiento de lo público a lo privado y lo íntimo, salida de las fronteras nacionales a través de una serie de subjetividades diaspóricas y nomádicas que cuestionan el propio concepto de literatura nacional. La violencia opera no sólo como tema y substrato socio-político y cultural de los textos, sino también como problema estético y formal. Esta literatura, por lo tanto, no sólo produce una renovación temática sino expresiva, lo cual supone el reto de imaginar nuevos espacios de lectura e interpretación para estos textos.

Este trabajo se concentra en este último aspecto al estudiar la función que tiene el reciclaje, la reescritura y la reinvención de una forma clásica y canónica, la metamorfosis, en este caso, en los textos centroamericanos de posguerra. Propongo la metamorfosis como otra forma, otra mirada o perspectiva desde la cual acercarse y reflexionar sobre la literatura de posguerra centroamericana. Para tal propósito, se estudia, en la primera sección, la novela de Horacio Castellanos Moya, Baile con serpientes, en diálogo con la propuesta teórica de Giorgio Agamben sobre los límites entre lo animal y lo humano. En la segunda sección, se analiza El cojo bueno, relato de Rodrigo Rey Rosa, donde me interesa establecer la relación que propone esta obra entre la metamorfosis y lo abyecto. Para ampliar este asunto, he tenido en cuenta el texto Poderes de la perversión, de Julia Kristeva y el cuento "Allal”, de Paul Bowles, texto que dialoga directamente con la narración de Rey Rosa. Finalmente, en la tercera sección se comenta "Yo, cocodrilo”, cuento contenido en El diablo sabe mi nombre, de Jacinta Escudos. El libro de Mary Douglas, Purity and Danger, me sirve para reflexionar cómo la metamorfosis hacia lo animal conlleva un traslado no sólo de lo humano, sino también hacia lo impuro, lo sucio.

No debería ser una sorpresa que en este momento de transición, renovación y reconstrucción la metamorfosis como subgénero literario y síntoma de una situación político-cultural adquiera gran importancia en muchas ficciones de posguerra. ¿Qué aprenderíamos de la literatura centroamericana de posguerra si nos acercáramos a ella a través de estas historias de metamorfosis? Me interesan las historias de metamorfosis porque son historias de cambio, de mutación, historias de progresión, de inestabilidad y de ambigüedad, y pueden servir para acercarse a una situación política, histórica y cultural que comparte todas las particularidades mencionadas anteriormente. Además, todas las historias de mutación referidas en este trabajo ponen en cuestión la propia definición de lo humano, de la humanidad, al incluir y fundirse con un otro que casi siempre es un animal o un espacio marcado por lo abyecto, lo impuro, lo negado, lo sucio, lo oscuro. La metamorfosis, esta especie de laboratorio, de teatro, es donde se

\footnotetext{
Revista Iberoamericana, Vol. LXXIX, Núm. 242, Enero-Marzo 2013, $163-180$
ISSN 2154-4794 (Electrónico)
} 
pueden encontrar síntomas, signos, indicios, huellas, que sirven de clave para leer el momento histórico, cultural y político en cuestión: la posguerra.

Se podría hacer una historia de la literatura a través de las diferentes metamorfosis que los textos literarios nos han contado. El mundo grecorromano sería imposible de entender sin la metamorfosis de Leda en cisne, de Dafne en árbol, de Júpiter en toro y de Lucio en asno, para citar sólo algunos ejemplos. Metamorfosis es el título y tema de la primera gran enciclopedia de mitos y símbolos en la antigüedad. La literatura medieval y renacentista no sería imaginable sin sus bestiarios y sin sus referencias mitológicas. Por último, para muchos, la literatura moderna nació con el relato de una metamorfosis: Gregorio Samsa transformándose en un insecto.

Antes de seguir, es importante hacer una breve referencia a la última de estas metamorfosis por las múltiples afinidades que tiene con el corpus que se estudia en este trabajo. No era un sueño, nos dice Kafka. La metamorfosis ocurre en el mundo diurno, en el medio de la cotidianidad: la presión de los deberes, la obsesión con no llegar tarde al trabajo, la presión de la familia y del jefe se mantienen. Samsa no se preocupa por encontrarle una explicación a su metamorfosis, sólo le preocupan las consecuencias que este cambio tendrá en su vida práctica. Su entorno se mantiene intacto, sólo su cuerpo, y por ende su apariencia, su capacidad de moverse, sus hábitos alimenticios y su relación con los otros se ven afectados. Lo entiende todo pero su lenguaje es ininteligible. Su mundo interior parece mantenerse intacto; sin embargo, se han roto las vías de comunicación entre ese mundo y el exterior: su lenguaje y su apariencia, su cuerpo. El drama de Gregorio Samsa ocurre entre la irrenconciliable división que se produce entre su mundo interno y su mundo externo, entra la "pureza" de sus sentimientos burgueses, lo asqueroso y repugnante de su apariencia y hábitos alimenticios. Es la separación entre la carga afectiva de su entorno cuyo emblema es el retrato de la señora de pieles y sus nuevas necesidades locomotoras que necesitan de todo el espacio que le brinda la habitación para poder moverse. La muerte la causa su irreconciliable necesidad del afecto y de la cercanía humana y la contraria necesidad fisiológica que tiene su cuerpo de alimentos putrefactos, de los desechos de lo humano, de todo lo que los humanos expulsan, desechan, sacan de su entorno más propio y más cercano. Esta incongruencia, como bien captaron Deleuze y Guattari, ${ }^{1}$ tiene un carácter más cómico que trágico. Por eso, la obra tiene un final feliz. La familia burguesa prospera y la hija en la plenitud de su belleza física y con un puesto de trabajo está lista ya para buscar marido y fundar un nuevo hogar feliz. Hay una secreta relación entre la muerte del insecto, vinculado a los desechos y a lo putrefacto, y la felicidad y el orden de la sociedad y la familia.

La metamorfosis, en los autores que se presentan aquí (Horacio Castellanos Moya, Rodrigo Rey Rosa y Jacinta Escudos), es un mecanismo retórico-narrativo que, más que

1 Ver Kafka. Por una literatura menor, de Gilles Deleuze y Felix Guattari.

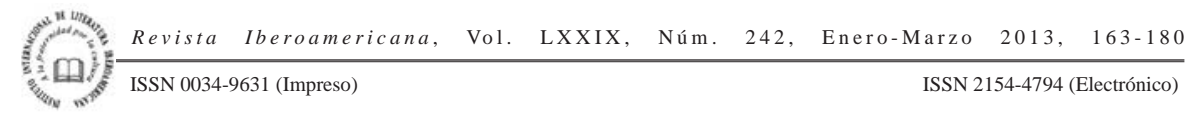


fijar una forma que prefigure ciertas identidades y roles sociales, traza la cartografía de un devenir, las siluetas de una huida. La metamorfosis, si se permite usar el oxímoron, es la forma de lo amorfo, de lo que carece de forma o de lo monstruoso, de lo que tiene múltiples formas incongruentes entre sí. La forma de lo que carece de nombre, de identidad, de un perfil fijo y reconocible. Asimismo, es la forma donde se acogen todas las anomalías, patologías y desórdenes que son descartados por los sistemas de regulación, control y orden que la sociedad postula. La metamorfosis, en estos autores, es a la vez cifra y síntoma de los espacios sociales y políticos desde los cuales sus textos se escriben y hacia los que sus textos aluden, que debido al carácter diaspórico de esta literatura no siempre coinciden.

\section{BAILE CON SERPIENTES}

La novela Baile con serpientes, del hondureño-salvadoreño Horacio Castellanos Moya, es un primer buen ejemplo para descubrir las particularidades de la literatura de posguerra centroamericana mencionadas al principio de este artículo. La metamorfosis que cuenta esta historia ocurre a través de un crimen. El asesino, Eduardo Sosa, sociólogo desempleado que vive arrimado con su hermana, usurpa la personalidad y la vida de su víctima: Jacinto Bustillo. Jacinto era un contador pero, debido a un escándalo causado por la relación amorosa con su secretaria, pierde tanto el empleo como su casa y termina viviendo como "desamparado" en su propio auto. La usurpación de Eduardo no se limita a la simple suplantación de la identidad, del nombre. Esta usurpación desarrolla matices corporales, psicológicos e incluso ontológicos. El suplantador adquiere varios de los rasgos físicos del usurpado (su barba, su cojera) y también sus hábitos (el alcoholismo). El usurpador, incluso, llega a realizar la venganza que su víctima sólo se atrevió a soñar: el asesinato del esposo de su amante (la secretaria) y de la esposa de Jacinto Bustillo.

La usurpación, la metamorfosis, ocurre en el único espacio que le pertenecía a la víctima, un Chevrolet amarillo donde vivía Jacinto Bustillo y que un buen día apareció estacionado en el barrio donde vive Eduardo Sosa con su hermana. Vale la pena citar el momento en que Eduardo Sosa, luego de haber asesinado a Jacinto Bustillo, entra por primera vez en el auto-casa-refugio de Bustillo:

Enfilé sin dilación hacia el Chevrolet amarillo, abrí la portezuela y me metí de golpe a la boca oscura. El tufo rancio casi me noqueó [...]. El lugar, extraordinariamente ordenado, sin asientos, con sólo un pequeño taburete, evocaba la cabina de una nave: ringleras de frascos y botes de laja semejaban tableros y controles; un par de mantas y otros trapos estaban apilados en una esquina. Sentí una alegría inédita, abrumadora, porque ese espacio ahora me pertenecía, era sólo mío, para siempre. (22-23)

\footnotetext{
ISSN 0034-9631 (Impreso)
} 
Antes de continuar, es necesario prestar atención a la singularidad de este espacio no sólo por la importancia que tiene dentro de la historia (lugar donde ocurre la mutación y desde el cual se llevará a cabo la serie de crímenes que cuenta), sino también por la relevancia que tiene para entender su carácter político. Lo primero que llama la atención es el contraste que hay en este espacio entre lo fétido, la pobredumbre que encontramos en él, y el carácter ordenado y futurístico que, incluso, se podría definir como utópico. Este espacio (el primero que Eduardo Sosa considera propio) es, además, un espacio móvil y nómada, un espacio que se opone a la sedentaria, privada y burguesa vida familiar y laboral. Igualmente, este espacio era el que le había permitido a Jacinto Bustillo, y ahora a su suplantador, "[dormir] por temporadas en distintas zonas de la ciudad, lejos de la mugre que los demás llamábamos familia, prestigio, trabajo” (18). Si la casa y el trabajo son los lugares que reafirman la identidad, la estabilidad, las seguras fronteras entre lo público, lo privado y lo íntimo, el carro amarillo funciona en este texto como un laboratorio donde tienen lugar los flujos, las mutaciones y las transformaciones. Es un espacio en movimiento y en constante cambio donde las fronteras entre lo propio y lo ajeno, lo puro y lo impuro, lo sagrado y lo abyecto, el afecto y la aberración, lo lícito y el crimen, y lo animal y lo humano, están en constante proceso de transformación y redefinición. Este lugar es el que nos propone Castellanos Moya para pensar y reinventar lo político, debido a que allí los límites, las identidades y las fronteras están en constante proceso de cuestionamiento y redefinición.

Por último, y esto tal vez es lo más importante, es en este espacio donde el protagonista aprende a convivir, a comunicarse, e incluso a amar y a matar con esos otros seres vivos no-humanos, que por eso mismo lo limitan y definen de la frontera de lo humano: las serpientes. Es en ese auto donde Eduardo Sosa las percibe por primera vez. Vale la pena citar en extenso ese pasaje:

[S]entí aquellas viscosidades untándose a mi cuerpo, delizándose lenta, asquerosamente. El terror me paralizó. No cabía ninguna duda: eran culebras, serpientes quién sabe de qué clase, que habían estado escondidas en las ranuras del auto. [...] Distinguí por lo menos media docena de ofibios que reptaban sobre mi pecho, alrededor de mis piernas [...]. ¡Claro!: eran las mascotas de Don Jacinto, las sustitutas de aquella mujer y aquella hija que lo habían despreciado rastreramente. Si lograba controlarme un par de minutos más, si me concentraba profundamente para que ellas sintieran mis vibraciones y comprendieran que yo era el nuevo Don Jacinto, entonces estaría salvado [...]. Estuve como cinco minutos inmóvil, sintiéndome Don Jacinto, pensando que la navaja cacha color hueso que portaba en mi bolsillo había sido una especie de escalpelo gracias al cual había abierto tremenda hendidura para penetrar en el mundo en que quería vivir. [...] Empecé a murmurar, a decirles, a contarles que el viejo mugroso se había transmutado en quien ahora les hablaba. [...] Y ahí íbamos, radiantes, avanzando a toda máquina-el Chevolet amarillo, las serpientes y yo-, ganosos de llegar a otras zonas de la ciudad, donde iniciaríamos la aventura de una nueva vida. (23-25)

ISSN 0034-9631 (Impreso) 
Las serpientes son las causantes de la mutación de Eduardo Sosa en Jacinto Bustillo: para poder convivir con serpientes hay que saber, al igual que ellas, cambiar de piel. Es mucho más justo en este caso hablar de cambio de piel que de cambio de identidad. Los personajes trastocados viven en los márgenes de la sociedad; carecen de hogar propio y empleo, las dos instituciones que garantizan la estabilidad y la identidad en la sociedad moderna, carecen del estatus social mínimo que permitiría hablar de un intercambio de identidades. Es en este espacio, el primero que Eduardo Sosa-Jacinto Bustillo considera como propio, donde descubrirá una nueva forma de convivencia, un nuevo sentido de la comunidad, una diferente forma de vivir su humanidad e inhumanidad.

Giorgio Agamben, en su libro Lo abierto. El hombre y el animal, define la primera frontera política como esa zona que el hombre delimita dentro de sí mismo para diferenciarse de lo animal. Esa zona es un umbral biológico-cultural-político a partir del cual los hombres empiezan a definir lo que constituye la dignidad inalienable de la vida humana, esos mínimos requerimientos sin los cuales una vida humana no merece ser vivida ante y contra los otros seres vivos; esto también trae como inevitable consecuencia que muchos seres humanos queden excluidos de la definición de lo humano. "El conflicto político decisivo, que gobierna cualquier otro conflicto, es, en nuestra cultura, el que existe entre la animalidad y la humanidad del hombre. La política es, así pues, al mismo tiempo y desde el mismo origen biopolítica” (102). Cuando se interroga la dignidad humana, los sentidos y los valores que conforman este concepto, lo que se cuestiona es esa zona que une, y a la vez separa, la vida de lo político, al hombre de lo animal y a los hombres entre sí. La política es el arte de la demarcación de esas fronteras, de la distinción de esos territorios. Sin embargo, para que un texto literario pueda ser definido como político no debe limitarse a reproducir estas divisiones, a representar estos territorios, sino que tiene que desmontar esa maquinaria política donde se genera la definición de lo humano a partir de la exclusión, negación e incluso exterminio de otros seres humanos, y otros seres vivos, a los que se le niega la dignidad, el carácter inviolable y sagrado que se asocia con la vida que se considera humana:

[En] nuestra cultura, el hombre -lo hemos visto- ha sido siempre el resultado de una división y, a la vez, de una articulación de lo animal y de lo humano, en que uno de los dos términos de la operación era también lo que estaba en tela de juicio. Hacer inoperante la máquina que gobierna nuestra concepción del hombre significa por tanto no ya buscar nuevas -más eficaces o más auténticas-articulaciones, como exhibir el vacío central, el hiato que separa -en el hombre-al hombre y al animal, aventurarse en este vacío: suspensión de la suspensión, shabbat tanto del animal como del hombre. (114, énfasis mío)

Más que generar nuevas definiciones de lo humano con sus inevitables desechos, restos, excrecencias que son consideradas inhumanas, el texto de Castellanos Moya nos coloca

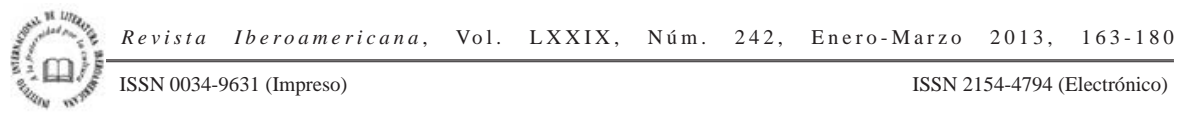


en esa frontera movible donde lo humano y lo inhumano se construye y desarticula. La convivencia que se genera entre Eduardo Sosa-Jacinto Bustillo y sus serpientes se realiza en un espacio de constante mutabilidad donde las fronteras entre lo propio y lo ajeno, la identidad y la alteridad, la animalidad y la humanidad tanto se funden y se mezclan como divergen y difieren.

Se produce un acercamiento inédito entre lo animal y lo humano: las serpientes entienden el lenguaje humano y conversan con Eduardo-Jacinto. Tienen nombre propio y una identidad definida. Esto, sin embargo, no significa que se asimilen totalmente a la esfera de lo humano. Sus instintos se mantienen intactos. No conocen la piedad, ni la conmiseración y sienten un gran placer cada vez que envenenan a sus víctimas. Eduardo-Jacinto, por su parte, no tiene una identidad fija, vive entre los desechos y se alimenta de ellos. Tiene una insaciable necesidad de matar, pero esto no lo animaliza totalmente. Es también calculador, astuto y extremadamente sagaz para huir de la policía. Lo que se produce en el texto es esa convivencia y constante mutación entre lo animal y lo humano, entre lo inhumano y la humanidad.

La segunda parte de la novela nos presenta la maquinaria político-policial que trata de descifrar los crímenes en serie que han cometido Eduardo-Jacinto y sus serpientes y de descubrir a sus autores. La máquina paranoica del estado se desata y empiezan a aparecer teorías conspiratorias sobre las supuestas causas, autores y motivos de los crímenes. Estos crímenes que se colocan más allá de las fronteras del sentido y del control, generadas por el estado, revelan la precariedad, arbitrariedad e inestabilidad del orden establecido. Los crímenes recuerdan y superan al caos que vivió esa sociedad, que debido a la mención de la Colonia Escalón podemos suponer que es la salvadoreña en la época de la guerra: “el aullar de las sirenas, el denso humo, el crujido de las llamas, los cadáveres, los autos achicharrados, la gente moviéndose enloquecida: ni en tiempos de la guerra se vio algo semejante" (80). El desorden se extiende al mismo aparato legal ya que el crimen cometido tanto por Eduardo-Jacinto como por sus serpientes resulta imposible de procesar a nivel jurídico y, por lo tanto, se convierte en ilegible, inclasificable ante la propia ley: “las serpientes no pueden ser procesadas judicialmente” (106).

Hacia el final de la novela, Eduardo-Jacinto hace una llamada a una de las reporteras que ha seguido este caso de crímenes en serie para revelarle la causa, el secreto que se esconde detrás de los mismos: "No hay plan, no hay conspiración, como acaban de decir en la radio. Sólo el azar y la lógica que me permiten profundizar mi mutación. Pero ustedes no lo entenderían” (138). Esta llamada desinfla la máquina de relatos, la máquina ideológica par excellence, del estado. La verdadera causa del crimen, confiesa EduardoJacinto, es profundizar en su mutación. Ser capaz de vengar a su víctima, atreverse a realizar lo que él simplemente soñó. Destruir a quienes destruyeron a Jacinto Bustillo: su esposa y su hija y el marido de su amante. El asesino reencarnando en su víctima, viviendo y padeciendo la vida de éste de un modo que ni la propia víctima se atrevió a

\footnotetext{
Revista Iberoamericana, Vol. LXXIX, Núm. 242, Enero-Marzo 2013, $163-180$
ISSN 2154-4794 (Electrónico)
} 
hacer. Al profundizar en su mutación es capaz de convivir, de crear una comunidad con sus nuevas compañeras-amantes, las serpientes. Viven en una zona donde la distinción entre lo animal y lo humano, entre la humanidad y la inhumanidad del hombre queda suspendida y se vive en un constante devenir, en un ir y venir entre ambos polos. Dice Agamben en su libro antes citado:

\begin{abstract}
Y si un día, según una imagen ya clásica, el “rostro de arena” que las ciencias del hombre han plasmado sobre la línea de playa que visitan las olas de nuestra historia hubiera de borrarse definitivamente, lo que aparecerá en su lugar no será un nuevo mandýlion o la "verónica” de una humanidad o de una animalidad reencontradas. Los justos con cabeza de animal de la miniatura de la Ambrosiana no representan tanto una nueva declinación de la relación hombre-animal, como una figura de la "gran ignorancia" que deja ser a uno y otro fuera del ser, salvados en su ser propiamente insalvable. (115)
\end{abstract}

No hay que volver a definir al hombre y lo humano, y, por ende, generar nuevas exclusiones, nuevas áreas de inhumanidad. Lo que hay que hacer más bien es atreverse a vivir en esa zona de indistinción, de ignorancia, entre lo animal y lo humano, entre la vida y lo político.

EL COJO BUENO

El epígrafe de Baile de serpientes sirve de puente entre esta novela y la que ahora se va a analizar: El cojo bueno, del guatemalteco Rodrigo Rey Rosa. La cita en cuestión, una traducción de dos fragmentos de uno de los cuentos más conocidos de Paul bowles titulado “Allal”, dice lo siguiente:

-Las serpientes son como las personas-declaró-. Tienes que llegar a conocerlas. Entonces puedes hacerte amigo de ellas.

-¡Buscad a mis serpientes! ¡Ayudadme a encontrar a mis serpientes! (Baile 7)

En El cojo bueno Rodrigo Rey Rosa recrea el encuentro ficticio entre el escritorprotagonista de la novela y Paul Bowles en Tánger:

Durante la cena, Juan Luis conversó con Bowles acerca de sus narraciones.

-En un cuento suyo titulado "Allal” ocurre un intercambio de conciencias-le dijo.

-Todo en mis cuentos son suposiciones. Si algo así como un intercambio de conciencias fuera posible, sin que intervengan los signos y las palabras, sucedería de esa manera. Pero sabemos que no es posible.

-Pero ¿cree en la telepatía?

-Sí. Creo que la comunicación telepática es posible. Pero eso no implica un intercambio de conciencias como el que ocurre en “Allal”. (68-69)

Revista Iberoamericana, Vol. LXXIX, Núm. 242, Enero-Marzo 2013, $163-180$
ISSN 2154-4794 (Electrónico) 
Juan Luis, el protagonista de la novela, habla con Paul Bowles sobre sus narraciones, pero el único texto que menciona directamente es “Allal”. Es necesario detenerse, aunque sea muy brevemente, en esta historia de Bowles a la que la novela de Rey Rosa otorga tanto valor. Tres razones justificarán esta pequeña digresión: a) la importancia que tiene el encuentro con Paul Bowles en la economía de esta novela; b) la concepción que el Paul Bowles ficcional que recrea este texto tiene de la literatura (el carácter conjetural del ejercicio literario que se dedica a recrear hechos considerados imposibles en la realidad); c) la relación maestro-discípulo que propone el texto entre Paul Bowles ${ }^{2}$ y Juan Luis Luna y la forma elíptica ${ }^{3}$ (casi secreta) en la cual el texto de Rey Rosa reescribe y reinventa la narración de esa voz magisterial; la forma en que un texto centroamericano actual se coloca ante la voz de un maestro.

“Allal” nos cuenta la historia de una metamorfosis. El protagonista de la novela, un niño abandonado por su madre, esclavizado por las personas que lo recogen y maldecido por los miembros del pueblo en donde vive ${ }^{4}$ logra transmigrar su alma al cuerpo de una serpiente. Como no es fácil, en poco espacio, hacerle justicia a la riqueza y complejidad del relato de Bowles, me detendré en la escena que más relevancia tiene para la novela El cojo bueno, de Rey Rosa. La escena narra la primera visión que tiene Allal luego que ha empezado a vivir en el cuerpo de la serpiente y la relación que tiene el protagonista con esta nueva piel, esta nueva apariencia exterior: "He opened his eyes and saw, very close to him, what looked like the flank of an enormous beast, covered with coarse stiff hair” (494). Su cuerpo visto desde fuera se hace irreconocible, totalmente ajeno, adquiere características monstruosas. La piel ajena, la piel del animal temido y adorado, se adecúa al alma propia como ningún otro cuerpo lo ha hecho: "There was no feeling of having a body, for he was perfectly contained in the skin that covered him” (495). La piel, la cubierta exterior, funciona ahora como otro pliegue de la interioridad. Allal ha encontrado en la piel de la serpiente, ese animal que vive al igual que el hombre en

2 El propio Rey Rosa se refiere a este supuesto primer encuentro con Paul Bowles en los siguientes términos: "Supongo que soy responsable de que ese episodio de El cojo [...] sea interpretado como la narración de ese 'primer encuentro', pero es pura ficción. Es lo que yo imaginé que pudo ser, de no haber conocido a Bowles años antes y en el contexto de un taller de narrativa, o sea, de una manera más trivial. Aparte de las lecciones de precisión y claridad implícitas en sus textos, y lo que de ellos pude aprender mediante la traducción, por él me di cuenta de que era posible organizar la existencia, la vida, alrededor de la práctica de la escritura” (“Escritura”).

3 La relación oblicua, indirecta, casi invisible que mantiene Rey Rosa con la historia de Bowles enfatiza, a mi modo de ver, la importancia que ésta tiene para la novela de Rey Rosa que se analiza aquí; por eso, no se ha comentado anteriormente la relación entre Baile de serpientes, de Horacio Castellanos Moya, y el cuento de Paul Bowles, aunque es mucho más directa.

4 "The people of the town, who never allowed him to forget that he was the son of sin, and therefore not like others, but meskhot-damned" (488).

ISSN 0034-9631 (Impreso) 
las fronteras de lo animal pero desde el polo opuesto, en las antípodas de lo humano, ${ }^{5}$ su verdadero refugio, su lugar más propio. Un lugar en que el adentro y el afuera, la interioridad y la exterioridad, lo humano y lo bestial se funden y confunden.

Esta dialéctica entre la extrañeza y la pérdida parcial del cuerpo propio y la recuperación de la vivencia de la propia corporalidad a través de un elemento extraño y ajeno es central en la economía textual de la novela de Rey Rosa. El cojo bueno narra una historia donde se mezclan la violencia de una sociedad marcada irreversiblemente por la guerra, la abyección inherente a un miembro mutilado del cuerpo y la serie de afectos que esto genera, así como la historia de un escritor joven que trata de acercarse a una figura consagrada. Cualquier interpretación de esta novela tiene que ser capaz de hilvanar todas estas tramas que la componen y los espacios en que estas tramas ocurren: la ciudad de Guatemala y Tánger. La historia se podría leer también como una novela de aprendizaje, de iniciación de un escritor. El aprendizaje de la escritura de Juan Luis Luna, el protagonista de la novela , a través de las cartas que le escribe a su padre donde trata de conmoverlo para que éste pague por su rescate y, de esta manera, salvar su vida. Dos de estas cartas le llegan al padre con partes mutiladas de su cuerpo. El aprendizaje de la escritura en este libro está vinculado a la mutilación y también a la prótesis, al miembro artificial que cumple la función de la parte mutilada.

Interesa aquí resaltar tres aspectos capitales para poder entender cómo esta novela dialoga y forma parte de la narrativa centroamericana de posguerra: a) el aprendizaje de la escritura en una sociedad marcada por la guerra y la violencia; b) la abyecta relación que se tiene con el cuerpo ajeno y el propio a partir de los traumas causados por la mutilación y el injerto, la prótesis; c) la relación que propone este texto entre el acercamiento al escritor que se admira, a la figura de autoridad, y el regreso de un pasado traumático vinculado a la violencia y a la mutilación corporal.

En la primera escena, Juan Luis Luna, el protagonista, ha sido secuestrado y es forzado por sus captores a escribirle cartas a su padre distante e indiferente tratando de convencerlo para que pague su rescate. El secuestro ha ocurrido en la Ciudad de Guatemala y Juan Luis es mantenido por sus captores en "un hoyo profundo y oscuro revestido de metal oxidado donde había un fuerte olor a gasolina” (25). Irónicamente son sus propios secuestradores quienes le instan, lo fuerzan, a convertirse en escritor: "Te vamos a dar pluma y cafecito y después te ponés a trabajar. A ver si te convertís en escritor” (26). Rodrigo Rey Rosa realiza una parodia grotesca de uno de los temas preferidos de la literatura occidental moderna: el aprendizaje de la escritura, la formación

5 Ver Diccionario de símbolos, de Jean Chevalier y Alain Gheerbrant: “Tanto como el hombre, pero contrariamente a él, la serpiente se distingue de todas las especies animales. Si el hombre se sitúa al término de un largo ‘esfuerzo genético’ deberíamos también, necesariamente, situar a semejante criatura fría, sin patas, ni pelos, ni plumas, en el comienzo del mismo 'esfuerzo'. En ese sentido, hombre y serpiente son opuestos, complementarios y rivales” (925).

Revista Iberoamericana, Vol. LXXIX, Núm. 242,
ISnero-Marzo 2154-4794 (Electrónico) 
del escritor. Las partes mutiladas del cuerpo de Juan Luis, el dedo que acompaña a la segunda carta, el pie que acompaña a la tercera, son mucho más elocuentes que las palabras. Estas cartas hablan con la violencia de los miembros amputados del protagonista. La transformación, la metamorfosis de Juan Luis en escritor está marcada, acechada (haunted), por la elocuencia brutal y muda de su cuerpo mutilado.

La segunda escena, que interesa destacar, ocurre cuando la novia y el padre de Juan Luis reciben un largo sobre negro que contiene uno de los miembros mutilados, el pie. Esta escena, por su importancia en la novela, se cita en extenso:

Dentro encontró lo previsto: el pie amputado de su hijo envuelto en una gasa con sangre dentro de una bolsa plástica con cierre de presión. [...]

-¿Estamos seguros de que es de él?

Ella asintió con la cabeza [...].

Tenía el poder de repeler las miradas; sin embargo en cuanto dejaban de observarlo, comenzaba a actuar como un poderoso imán, convertía sus miradas en agujas de hierro. [...] -Es necesario cerciorarse-dijo, pero no se movió-. Pero en su carta pide que congelemos el pie, por si cuando salga pudieran enmendárselo. [...]

Lo tocó con un gesto de ciego y luego se echó hacia atrás pero siguió mirándolo. [...] El contacto entre su mirada y la parte donde el pie había sido cortado, donde podía verse un círculo de carne roja, en los bordes ya un poco negruzca, con el círculo concéntrico del hueso blanco, vidrioso y lechoso al mismo tiempo, no era comparable al contacto de sus pupilas con otros objetos ordinarios ni con otros objetos de arte. (38-39, énfasis mío)

El miembro amputado que ha usurpado el lugar del lenguaje, que ha provocado toda la atención y conmoción que las palabras no pudieron lograr, tiene ese carácter ambivalente que caracteriza a lo sagrado y lo abyecto: fascinante y horroroso, extraordinariamente conmovedor y profundamente repulsivo. "La naturaleza de lo sagrado”, como apunta Kristeva, tiene la singularidad de ser "peligros[a], inquietante, interdict[a] e incluso impur[a]” (81). Lo sagrado se vive primero como tabú y luego como totem, primero como impureza y luego como purga, catarsis. En el caso que nos ocupa, el miembro amputado es a la vez irreconocible e irreductiblemente extraño, imposible de ser vinculado con certeza a Juan Luis y, al mismo tiempo, conmovedoramente cercano, íntimo, un inapelable recordatorio de la vida del hijo que peligra y que necesita ser rescatada sin mayor demora. El miembro mutilado activa la economía afectiva que las palabras fueron incapaces de generar. El aprendizaje de la escritura, el control sobre las palabras y sus silencios, de los afectos y reticencias que provoca el lenguaje sólo es realizable en este texto de Rey Rosa a través de la pérdida de la integridad física, de la mutilación violenta y por manos ajenas del propio cuerpo. El texto de Rodrigo Rey Rosa constituye una profunda reflexión política sobre las circunstancias de la escritura en sociedades marcadas por un pasado y un presente violento como las centroamericanas.

Revista Iberoamericana, Vol. LXXIX, Núm. 242,
ISSN 0034-9631 (Impreso) 
En la tercera escena que se debe comentar, encontramos a Juan Luis Luna ya convertido en escritor y llevando una prótesis del miembro mutilado. Si el aprendizaje de la escritura se vinculaba a la mutilación, la transformación en escritor está relacionada a la prótesis. Ha salido de su país debido al trauma de su mutilación y secuestro. Ha vivido en Nueva York, luego en Madrid, y lo encontramos ahora viviendo en Tánger ya que: “en Marruecos le sería mucho más fácil conseguir el cáñamo que se había acostumbrado a consumir a diario después de la amputación” y además porque “sabía que Paul Bowles vivía en Tanger” (56). Esta escena ocurre unos días antes de la conversación con el ficticio Paul Bowles, ya comentada anteriormente. En este momento, Juan Luis Luna se limita a visitar los lugares frecuentados por Paul Bowles pero no se atreve a hablar con el escritor, pues considera que todavía la distancia que los separa es infranqueable. La escena ocurre en un lugar llamado Montecarlo, uno de los preferidos de Bowles. De nuevo, cito extensamente, por lo significativo de la escena:

El mâitre d’hôtel fue hasta la mesa de Bowles a saludarlo. Juan Luis [...] no podía apartar los ojos de aquella mesa por períodos demasiado largos [...]. El marroquí regresó a la cocina y poco después volvió a la mesa de Bowles, seguido por un hombre cuya aparición tuvo en la espalda de Juan Luis el efecto de un cubo de agua fría. El mâitre d’hôtel lo presentó a Bowles y su comitiva como monsieur Pérez, el propietario. [...] La voz del propietario [que conversaba con Paul Bowles] llegó a los oídos de Juan Luis como si viniese desde muy lejos.

«Admiro mucho su trabajo -decía-. He leído todas sus novelas». [...]

-Disculpa-le dijo Juan Luis a Ana Lucía. Sin tomar su bastón, se levantó de la mesa y se fue cojeando hacia el rótulo que decía «Toilettes».

Se miró en el espejo: estaba pálido. Se arqueó sobre el inodoro y vomitó. Monsieur Pérez tenía no sólo el aspecto sino también la voz del hombre que lo había mutilado [...]. (59-60)

La distancia que parecía separarlo irremisiblemente del escritor que admira se ha borrado de repente. Ahora tiene otro motivo para conversar con Paul Bowles, estar cerca de aquel hombre que le mutiló su cuerpo, vengarse de él. La mutilación, el trauma, el recuerdo de un pasado violento, la necesidad de restitución y de venganza borran esa barrera simbólica que distanciaba al escritor novel del consagrado, al joven escritor latinoamericano del "maestro occidental”. Ahora se aclara mucho mejor por qué Juan Luis Luna sólo se refiere al relato "Allal” en su encuentro con Paul Bowles. Este cuento termina con la historia de una venganza, de la restitución de una injusticia de manera violenta. El niño, negado, marginado, borrado y silenciado por la comunidad de los hombres asume su destino bestial y se venga de los hombres usando los nuevos dotes que le otorga su cuerpo de serpiente: "Allal had the joy of pushing his fangs into two of them before a third severed his head with an axe" (496). Allal solventa su irreconciliable distancia con el mundo humano matando hombres y muriendo a manos de éstos.

\footnotetext{
Revista Iberoamericana, Vol. LXXIX, Núm. 242, Enero-Marzo 2013, $163-180$
ISSN 2154-4794 (Electrónico)
} 
Rodrigo Rey Rosa, sin embargo, en su novela reescribe el final de "Allal”. La inminencia de la venganza que llena de suspenso a una novela como El cojo bueno nunca llega a cumplirse. Juan Luis descubre a sus secuestradores, los confronta, los amenaza veladamente. Pero la venganza nunca se materializa. El autor, en el año 2002, se refiere al final de su novela en los siguientes términos:

El tema del secuestro es recurrente en la vida de los guatemaltecos, lo mismo que la
amenaza de muerte y la persecución. Además de representar una preocupación constante,
son como nuestra materia prima. Y lo mismo ocurre con el odio y el deseo de venganza
que resultan de los secuestros, las persecuciones, las amenazas y las muertes violentas.
Si en El cojo [...] la historia quiere resolverse por medio del perdón, es porque en el
momento de cerrar la trama me pareció más interesante sondear el impulso de no
venganza que el deseo de venganza, que es el más natural. ("Escritura”, énfasis mío)

El texto opta por una diferente forma afectiva de relacionarse con el pasado violento y traumático: el perdón. La literatura desafía a la realidad, a la política. La ficción imagina una salida conjetural, imposible y a la vez profundamente necesaria, para una sociedad ahogada por un pasado y un presente intolerablemente violentos. El protagonista de esta novela de Rey Rosa no sufre una metamorfosis animalesca ni se funde con un animal como el protagonista del relato de Castellanos Moya. La metamorfosis externa e interna de Juan Luis se entiende por la mutilación, consecuencia de la violencia que sufre que, a diferencia de Eduardo-Jacinto, no lo conduce a la venganza.

Podría decirse que la mutación de Juan Luis, aunque dolorosa y violenta, lo empuja hacia un camino donde la imaginación es el espacio de lo que debe ser humano (novenganza), la literatura lo ayuda a no desatar lo inhumano/lo animal (venganza) y Eduardo-Jacinto (¿por falta de imaginación?) se libera en el mundo de lo inhumano/lo animal. Aunque para Rey Rosa la venganza sería lo natural, en Juan Luis se personificaría la utopía del perdón y de la no-violencia en las sociedades centroamericanas que sería, en ese sentido, una metamorfosis de lo utópico al mutarse en realidad. En cambio, Eduardo-Jacinto experimenta una metamorfosis que, a medida que se consolida (EduardoJacinto-Serpientes), hace que su naturaleza humana descienda más con lo cual no hay un posible regreso (una metamorfosis regresiva) que lo vuelva a humanizar. El mensaje de la novela de Castellanos Moya es menos esperanzador, refleja el desencanto y la desilusión de los proyectos irrealizables de la posguerra.

“Yo, cocodrilo" en EL Diablo SABE MI NOMBRE

El Diablo sabe mi nombre, el último libro de Jacinta Escudos, continúa dentro de la línea de transgresión que caracteriza casi toda su obra. Las fronteras que se transgreden en este libro son múltiples: entre lo animal y lo humano, entre lo femenino

Revista Iberoamericana, Vol. LXXIX, Núm. 242, Enero-Marzo 2013, $163-180$
ISSN 2154-4794 (Electrónico) 
y masculino, entre la locura y la cordura, para mencionar sólo algunas. Este libro está lleno de seres mutantes, híbridos, andróginos. Son seres que cuestionan y deforman los sistemas clasificatorios con los cuales la sociedad organiza los roles y funciones de sus miembros. El terror y la abyección también habitan estas páginas. El hombre en “El espacio de las cosas” se despierta atrapado en una telaraña donde una gigantesca araña lo llena "de saliva tejiéndole una mortaja [...] que poco a poco comienza a tener el aspecto de una momia” (18). Convertido en insecto, está listo para ser succionado y presencia cómo se encuentra ya muerto en vida.

En “Película japonesa de los años 60” se narra la relación grotesca entre una langosta y un hombre donde se parodian películas de clase B japonesas en las que monstruos prehistóricos asolaban a los humanos. La convivencia entre monstruos y humanos se traslada a una escena doméstica, a la historia de una pareja disfuncional. Lo monstruoso coexiste con lo doméstico y lo familiar convive con lo más extraño: “tendrían un pleito monumental y él le lanzaría todas las conservas de la cocina [... ] y ella tendría que hacer uso de sus mandíbulas y tenazas para controlarlo” (82). Es el mundo al revés. Los sexos se trastocan, las fronteras se desdibujan y lo inimaginable adquiere realidad cotidiana. Rafael Lara Martínez nos dice en una reseña del libro que frente a "la bestialización de las diferencias, ante la persistente animalidad de lo humano, el único refugio sea tal vez la escritura”, y en otro momento agrega,

En un país que rehúsa asumir su pasado violento -honrar a los muertos en ceremonias cívicas-matanzas y serpientes se agitan en el recuerdo. Bullen fantasmas sin reposo. El Salvador es Comala [donde se] "urden los reflejos”. Su única "flor del espíritu santo" brota de "cavar fosas a los cementerios públicos” en nombre de lo extinto.

En El Salvador de posguerra, donde la memoria histórica se borra y el duelo no tiene cabida, donde la violencia social es el pan de cada día y la realidad cotidiana se codea con lo invivible, sólo queda una alternativa: una mutación, una metamorfosis hacia alguno de los lindes de lo humano. ${ }^{6}$

"Yo, cocodrilo" cuenta la historia de una niña que ante la eventualidad de tener que sufrir la mutilación de su cuerpo por la circuncisión femenina opta por transformarse en un animal que su comunidad considera monstruoso. "La niña que no se somete al ritual se convierte en cocodrilo” (71), le decían. Con este ritual, la comunidad se define y delimita a sí misma y a la humanidad de sus miembros. Optar por no hacerlo es transgredir la ley de ese grupo, significa estar más allá de lo que se considera humano y vivir en sus antípodas, convertirse, literalmente en un animal. Al no llevar acabo el ritual, la niña

6 Lara Martínez cita a Darwin para sugerir esta idea: "Las especies no son inmutables y su breve variación hacia lo ‘monstruoso' les concede mayor probabilidad de vivir en un mundo incierto”.

$\begin{array}{llllll}\text { Revista Iberoamericana, Vol. LXXIX, Núm. 242, } & \text { Enero-Marzo 2013, } & \text { 163-180 } \\ \text { ISSN 0034-9631 (Impreso) }\end{array}$ 
se convierte en paria, “[...] me dejaron a mi suerte. Madre no quería saber nada de mí [... no les importaba si me iba o me quedaba. Era indigna de todos” (73). La dignidad del ser humano, en este caso específico de ser mujer, también está ligada a este ritual. Es a través de este ritual, con la supuesta purificación que conlleva que las mujeres se convierten en miembros respetados y reconocidos por esta comunidad. La humanidad más que ser un dato, un hecho inherente al nacimiento, es producida a través del control que la tribu ejerce sobre el cuerpo de las mujeres y, por ende, su placer. El rito supone un segundo nacimiento donde a través de la mutilación la comunidad produce un nuevo cuerpo para sus mujeres. Ese cuerpo al que le ha sido atrofiado, extirpado su placer es un cuerpo político: un cuerpo que la comunidad ha creado a imagen y semejanza de sus fobias, de sus miedos a la impureza y al contagio. Fuera de este cuerpo político, de este cuerpo social, vive lo monstruoso, lo sucio, lo impuro.

A la niña que decide no someterse al ritual le dicen las otras mujeres que "será infiel, será lujuriosa, se enfermará de la carne y se le pudrirá todo. Sus partes le crecerán y crecerán y serán tan grandes como los cuernos de una cabra” (72). Esa niña fuera de la ley está también fuera de la dignidad humana: se pudre, es regida por su carne y la lujuria, se vuelve grotesca. Aunque sabe todo esto, la protagonista del cuento prefiere y decide "ser cocodrilo, indigna, impura" (73). Esa humanidad definida tanto por una ética (la dignidad) como por un dictamen sacro-religioso (la pureza) ejerce un control represivo. Ella prefiere habitar en los márgenes, ser excluida, incluso ser animal, antes de aceptar la ley de la comunidad.

En su libro Purity and Danger, Mary Douglas explica cómo estos rituales tan rígidos son una forma de estructurar las sociedades e imponer el orden. Al establecer leyes inamovibles que delimitan lo permitido y especifican el castigo que conlleva la transgresión, las sociedades le dan un semblante de orden a la experiencia humana que es siempre 'desordenada'. Douglas explica el fenómeno de la siguiente forma:

[...] ideas about separating, purifying, demarcating and punishing transgressions have as their main function to impose system on an inherently untidy experience. It is only by exaggerating the difference between within and without, above and below, male and female, with and against, that a semblance of order is created. In this sense I am not afraid of the charge of having made the social structure seem over-rigid. (4)

Rechazar y resistirse al ritual del grupo significa un desorden en la estructura de la comunidad y la contaminación del tejido social: “[...] if uncleanness is matter out of place, we must approach it through order. Uncleanness or dirt is that which must not be included if a pattern is to be maintained” (40). En este cuento, salirse de ese control supone ir hacia lo bestial, lo inhumano, lo monstruoso. La niña al transformarse en cocodrilo despierta el miedo hasta en otros animalitos: “[...] tienen miedo de que abra mis fauces. Tienen miedo de mis ojos" (71). Sus escamas, dientes filosos y "larga

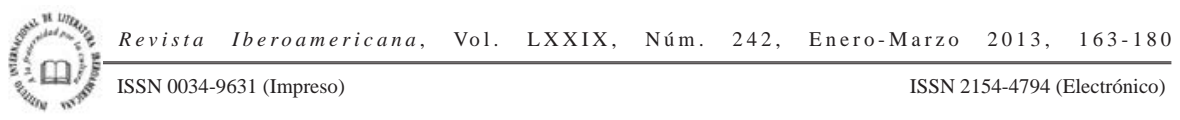


serpiente que le crece entre las piernas” (74) dibujan un ser con apariencia prehistórica y con un órgano ambiguo (pene-clítoris) que requiere cuidadosa observación para poder determinar su sexo. ${ }^{7}$ Su desobediencia de la ley la expulsa hacia un espacio contaminado, aberrante, bestial:

A polluting person is always in the wrong. [She] has developed some wrong condition or simply crossed some line which should not have been crossed and this displacement unleashes danger for someone. Bringing pollution, unlike sorcery and witchcraft, is a capacity which men share with animals, for pollution is not always set off by humans. (Douglas 113)

Después de haber cruzado ese límite de lo que su sociedad considera humano, propio y puro, la mutación es irreversible. Al traspasar esa frontera hacia lo animal, la niña deja atrás todos los sentimientos que se asocian con los humanos. Su transformación es una ruptura con sentimientos que, en teoría, definen la humanidad como, por ejemplo, el amor a la madre: "Madre murió y yo la vi morir, pero no sabía que su hija era yo, cocodrilo” (74). El regreso a su comunidad original, como líder de los cocodrilos, es una venganza con un toque de piedad (aunque brutal) al querer salvar a las niñas (así sea matándolas) del daño cometido por el pueblo:

Fuimos a la aldea. Destruimos todo.Alosúnicos seres que despedazamos fue a las mujeres de la aldea. Algunos compañeros murieron en la hazaña. Los hombres se defendían. Pero los hombres no nos interesaban. Eran ellas las que hacían todo. Las que cortaban, obligaban, mantenían las piernas abiertas. [...]. Participé personalmente en la comida de la curandera. Y nos encargamos también de todas las demás, porque las niñas no eran felices nunca, después del ritual. Fue un acto de piedad terminar con ellas. (74)

La transformación en cocodrilo le permite tomar la justicia por sus manos, le brinda libertad absoluta para estar fuera del control represivo de su sociedad y para ejercer con toda naturalidad sus instintos. Al final, la niña nos dice, "prefiero ser así, un cocodrilo con una larga serpiente que le crece entre las piernas” (74) recordándonos que en su escisión ${ }^{8}$ total con lo humano, ella finalmente logra tener, en proporciones gigantescas,

7 La ambigüedad que parece surgir con el órgano sexual de los cocodrilos encaja muy bien con la problemática de lo andrógino y mutante. La niña no sólo se convierte en animal, sino que al resistirse al ritual entra a ese espacio indeterminado donde no queda claro si la monstruosidad de su apariencia es por haberse convertido en cocodrilo o por poseer una 'serpiente larga entre las piernas' que podría ser un pene o quizás un clítoris gigantesco; como le advertían las mujeres de su comunidad "tus partes crecerán y crecerán” (72).

8 Llama la atención que la segunda acepción de esta palabra es "extirpación de un tejido o un órgano” ya que en cierto sentido, su ruptura con lo humano se lleva acabo precisamente para evitar la extirpación de la parte de su cuerpo asociada al placer.

ISSN 0034-9631 (Impreso) 
monstruosas y andróginas, un erotismo libre gracias a ese órgano amorfo e inclasificable que crece entre sus piernas.

En este cuento de Jacinta Escudos (que muy bien puede leerse e interpretarse desde una postura feminista, lo cual aquí no se hace pues nos alejaría del tema principal de este trabajo), la metamorfosis animalesca, como en la novela de Castellanos Moya, genera más violencia. La posible víctima de un ritual tradicional de su comunidad se resiste a que se ejerza la violencia contra ella, sin embargo, esa resistencia la conduce al mismo camino: no hay salvación, no hay un cambio hacia lo humano ni hacia la convivencia armoniosa. El marcado poder de su órgano y libre erotismo no la liberan. La niña se ha salvado de que la comunidad la transforme en un ser al que se le niega el placer; sin embargo, su metamorfosis en "un cocodrilo con una larga serpiente que le crece entre las piernas”, como si fuera el Narciso ovidiano, la enajena, la aliena y la aleja mucho más de lo humano.

En un primer momento, podría pensarse que ese órgano (que el ritual comunitario quiere destruir) hará de esta niña un ser diferente que podría transformarse y mutarse en un líder que liberaría a las demás niñas para que no sufran el castigo del ritual, pero no es así. La metamorfosis en un cocodrilo o la muerte son los dos únicos caminos para salvarse de la mutilación. Así pues, hay una escisión humana y social radical, el ser humano mutante o escindido pierde su humanidad (se convierte en cocodrilo vengativo) o se le niega parte de su humanidad (el erotismo libre y el placer sexual).

\section{CONCLUSIÓN}

En este trabajo he privilegiado el lado oscuro (y hasta siniestro) de la metamorfosis como reflejo y consecuencia del legado de la violencia, de la impunidad y de la forzada reconciliación que han tenido que sufrir estas sociedades centroamericanas donde no hay espacios reales para la memoria, el duelo, el perdón y el establecimiento de relaciones humanas en paz y armonía. Cabría preguntarnos, sin embargo, si la ficción de posguerra al presentarnos estas metamorfosis hacia lo monstruoso, bestial e impuro no nos está incitando a reflexionar sobre estas particularidades, que en la mayoría de las sociedades modernas se vinculan con lo inhumano, como un medio para expresar lo humano. En otras palabras, aunque parezca una contradicción, lo humano que vive una terrible guerra o el desencanto de la posguerra no encuentra otro camino o espacio que no sea lo inhumano para darle forma a su odio, su violencia, su venganza, su perdón, su amor o su pasión, lo que, en definitiva, también lo llena de humanidad. La metamorfosis, entendida como una forma que privilegia el devenir, el cambio, la mutación, podría servir también para reinventar nuevas formas de rememorar el pasado y de soñar el futuro. Quizás la libertad que alcanzan los protagonistas de Baile con serpientes y "Yo, cocodrilo” y el perdón con el que cierra El cojo bueno sean las claves para aprender a habitar ese pasado traumático y aprender a vislumbrar un futuro más esperanzador.

\footnotetext{
Revista Iberoamericana, Vol. LXXIX, Núm. 242,
ISSN 0034-9631 (Impreso)
} 
Agamben, Giorgio. Lo abierto. El hombre y el animal. Valencia: Pre-Textos, 2005.

Bowles, Paul. The Stories of Paul Bowles. Robert Stone, intro. Nueva York: Harper Collins, 2001.

Castellanos Moya, Horacio. Baile con serpientes. San Salvador: Dirección de Publicaciones e Impresos, 1996.

"La violencia...es parte de la salvadoreñidad". Entrevista por Rafael Menjívar Ochoa. Vértice en línea. 16 junio 2002. <http://www.elsalvador.com/ vertice/1002/06/16/entrevista.html>. 15 agosto 2009.

Chevalier, Jean y Alain Gheerbrant. Diccionario de los símbolos. Manuel Silvar y Arturo Rodríguez, trads. 6a ed. Barcelona: Herder, 1999.

Cortez, Beatriz. "Estética del cinismo: la ficción centroamericana de posguerra". Sóloliteratura. 18 julio 2000. <http://www.sololiteratura.com/hor/horestetica. htm>. 1 agosto 2008.

Deleuze, Gilles y Félix Guattari. Kafka. Por una literatura menor. México: Biblioteca Era, 1978.

Douglas, Mary. Purity and Danger. An Analysis of Concepts of Pollution and Taboo. Nueva York: Praeger, 1966.

Escudos, Jacinta. El Diablo sabe mi nombre. San José: Uruk, 2008.

Kokotovic, Misha. "Neoliberal Noir: Contemporary Central American Crime Fiction as Social Criticism”. Clues 24/3 (2006): 15-29.

Kristeva, Julia. Poderes de la perversión. Ensayo sobre Louis-Ferdinand Céline. Buenos Aires: Siglo XXI, 1989.

Lara Martínez, Rafael. "Lo que somos por dentro: El Diablo sabe mi nombre de Jacinta Escudos”. Periódico Digital El Faro. <http://www.elfaro.net>. 15 agosto 2009.

Ortiz Wallner, Alexandra. "Transiciones democráticas/ transiciones literarias sobre la novela centroamericana de posguerra”. Istmo: Revista virtual de estudios literarios y culturales centroamericanos 4 (2002). <http://collaborations.denison.edu/istmo/ n04/articulos/transiciones.html>. 15 agosto 2009.

Rey Rosa, Rodrigo. El cojo bueno. San Salvador: Dirección de Publicaciones e Impresos, 2001.

"Una escritura sin precipitaciones”. Entrevista por Claudia Posadas. Espéculo: Revista de Estudios Literarios (29). 2005. <http://www.ucm.es/info/especulo/ numero29/reyrosa.html>. 15 agosto 2009.

Rodríguez, Ana Patricia. "La producción cultural en Centroamérica bajo la égida del neoliberalismo”. Estudios culturales Centroamericanos en el nuevo milenio. Gabriela Baeza Ventura y Marc Zimmerman, eds. San José: Universidad de Costa Rica, 2009.

Revista Iberoamericana, Vol. LXXIX, Núm. 242, Enero-Marzo 2013, $163-180$
ISSN 2154-4794 (Electrónico) 